\title{
Institutions and economic change: some notes on self-organization, power and learning in human organizations
}

\author{
Giovanni Dosi $^{1} \cdot$ Luigi Marengo $^{2} \cdot$ Alessandro Nuvolari $^{1}$
}

Received: 12 December 2018 / Revised: 26 July 2019 / Accepted: 3 August 2019

(c) Eurasia Business and Economics Society 2019

\begin{abstract}
This paper provides a compact overview of the interpretations of the "primitive entities" constituting the social fabric of economic systems according to different social science traditions. In our view, it is possible to reconstruct two meta-narratives on the origins of the theoretical primitives which are at the roots of different social sciences approaches. The first narrative argues that 'once upon a time' there were individuals with well-structured and coherent preferences and with adequate cognitive algorithms which allowed them to take systematically rationally consistent decisions. At the beginning of history, they met and, conditional on the technologies available, undertook mutually beneficial exchanges or, when this was not possible due to technological non-convexities, trading difficulties or problems of contract enforcement, built organizations. In the alternative tale, at the beginning of history, there were immediately factors of socialization like families and social norms, which shaped desires, representations and, possibly, cognitive abilities of the agents. In this perspective, non-exchange mechanisms of interactions (authority, violence and persuasion) which establish the adaptation of agents to specific social roles appear in the explanation from the start. Here 'institutions' are the primitives, while 'preferences' and the very idea of 'rationality' are derived entities. Which of the two meta-narrative is chosen bears far-reaching implications for the interpretation of institutions and organizations and their transformations.
\end{abstract}

Keywords Institutions · Rationality - Self-organization · Hierarchies · Power · Endogenous preferences $\cdot$ Motivation

Alessandro Nuvolari

alessandro.nuvolari@santannapisa.it

Extended author information available on the last page of the article 


\section{Introduction}

A fundamental difference between social and natural sciences does not concern the methodology of the analysis but, even deeper, the "primitives" of the theory, in particular, the foundational assumptions concerning the nature of the social system and of the causal relationship among its constituting elements.

A classical physicist starting from bodies, masses, distances can tell a story of forces, interactions, etc. A quantum mechanics physicist starts from particles and waves. An evolutionary biologist starts with organic molecules and goes all the way up to multicellular entities, species, etc., all linked by mechanisms of mutation, recombination and selection, possibly on multidimensional nested scales.

What do we have in the social sciences? In our view, we have a much more limited common ground in terms of a shared "ontology" and, in particular, of the foundational "primitives" of the theory together with a much greater casualness in moving from the primitives to the formulation of analytical "tales" accounting for historical patterns of social and economic change.

In this paper, we provide a compact overview of fundamentally different ontologies of the social fabric of economic systems which underpin various social science approaches. We can start by highlighting two different perspectives that can be regarded as a sort of "extreme", opposing views concerning the foundational assumptions about the nature and reproduction of social systems. On the one hand, we have nearly theological axiomatizations about human behavior derived from simple invariant principles, by and large, rooted in "selfish", forward-looking rationality assumptions a la Becker (1976), whereas, on the opposite side, one can point to 'functionalist' or holistic theories of collective dynamics.

Interestingly enough, while there might be little scope for a constructive debate between these two extreme and "fundamentalist" perspectives, in practice, most interpretations of economic and social change acknowledge some role for both motivational micro-foundations and system-level effects. In our view, a fruitful reassessment of the 'foundational assumptions' rests precisely at this intermediate level, which is where major debates in social sciences have found their ultimate ground-from Hobbes to Smith all the way to Durkheim, Weber, Veblen, Schumpeter and Schmidt, just to name a few. Let us try to sketch out some of these foundational issues.

\section{Rationality and behaviors}

In our interpretation, the major ontological perspectives concerning the functioning of social systems are rooted in a number basic foundational assumption combined with "meta-narrative", which is basically a 'once upon a time' reconstruction of the primitives that feature in the theoretical interpretations. Needless to say, most scholars realize that these "meta-narratives" are nothing more than "fictitious tales of the origins" or "theoretical parables", useful for illustrating in 
a particularly stark manner the intuitions which underline the different notions. Still, we should acknowledge that they exert a powerful influence on the way in which the interpretative stories are told, on the assumptions of the models, on the selection and measurement of what are regarded as the key variables responsible for the emerging patterns of economic and social change.

In this paper, we shall use the term institutions in a very broad sense. Our notion of "institutions" covers, first, systems of rules, of what can and cannot be done (this meaning, of course, overlaps with the notion of institutions as "rules of the game" which is the staple of neo-institutionalism a la Douglass North), second, it includes, systems of prescriptions on what to do, from religious practices, to relational rules between parents and children, to social norms (a meaning which is closer to that familiar to sociologists). Finally, our notion of institutions also comprises explicit organizational forms from family and tribes, to parties, churches, state bodies, and indeed, business firms (a notion familiar to political scientists, at least before being colonized by neoclassical economics).

Pushing it to the extreme, as we see it, there are in the social sciences two archetypal ontological meta-narratives. According to the first meta-narrative, 'once upon a time' there were individuals with coherent preferences and with cognitive algorithms capable to solve the decision-action problems confronting them. They met in some clearing in the forest where they undertook mutually beneficial exchanges or, whenever this was not possible because of technological non-convexities, asymmetric information, moral hazard, built organizations. In this perspective, clearly, the 'primitives' of the tale are preferences, endowments and technologies (of production and exchange), while 'institutions' or 'organizations' are derived entities. In this ultimately functionalist approach, institutions emerge to address very specific economic needs of society (Ogilvie 2007). The research agenda for moving from primitives to derived entities is straightforward: in order to understand institutions we need to reconstruct the fundamental economic problem that they are addressing and to reconstruct the interactions among fully rational, self-interested individuals that has brought them into being. As Ogilvie (2007, p. 651) aptly puts it, within this framework, "whatever is, is right".

This research agenda has indeed being pursued vigorously by at least two generations of economists and economic historians, so that, today, a wide array of institutions such as craft guilds, sharecropping, serfdom, etc. has been reinterpreted using this "efficiency" framework. Note that the approach implicitly contains a view on the drivers of institutional change: when the primitives (preferences, endowments and technologies) change the prevailing institution may become no more efficient and so a new meeting in the opening of the forest is necessary in order to find more suitable arrangements. This, for example, is the approach adopted by North and Thomas (1973) in their reconstruction of European economic history from the Middle Ages to the Industrial Revolution. ${ }^{1}$

\footnotetext{
1 Interestingly enough, North after having endorsed the application to the study of institutional change of the perfect rationality framework (North and Thomas 1973; North 1981), in later contributions has vouched the adoption of a much more sophisticated approach, open to the role of bounded rationality and cognitive biases (North 2005). For a compact synthesis, see Nuvolari (2016).
} 
In the second and alternative tale, the premises are radically different: 'once upon a time' there were immediately factors of socialization, including some institutional structures and social arrangements like families or schools shaping desires, representations and, possibly, cognitive abilities of individuals by means of authority, violence or persuasion, ensuring in this way, the adaptation of agents to their social roles.

Non-exchange mechanisms of interactions appear in this second account from the very beginning. Here 'institutions' are the primitives, while 'preferences' and the very notion of 'rationality' are derived entities. These notions are very familiar indeed to several social disciplines, ranging from anthropology to social psychology to sociology (picking three out of a multitude: see Laing and Esterson 1970, on the family; Milgram 1974, on obedience; and Moore 1958, on social submission), with the notable of exception of contemporary economics!

Certainly, with enough refinements, both these crude tales can be reformulated in a more sophisticated ways, and in many instances, they can even become observationally indistinguishable. So, for example, in the 'rational' tale one can easily admit that preferences, too, are endogenous, but on a longer time scale. However, in principle, institutions and organizations ought to be considered relatively plastic and adaptable, while the interests, motivations and menus of strategies available to the agents ought to be relatively invariant. Conversely, in the 'institutionalist' tale it is easy to account for the influence of individual preferences and strategies upon the evolution of social organizations. However, one is inclined to view institutions as the relatively inertial entities and agents' motivations and behaviors as comparatively flexible and adaptive.

These foundational tales obviously shape also the approach adopted to study specific issues. Consider the question of "why we see organization $x$ at time $t$ ?". In the first perspective, one would start answering by focusing upon the interests of the agents involved in that organization, the tasks that the organization in question must carry out and the technologies available, and then try to reconstruct its existence to the intentional efforts of the agents to 'do their best', given the constraints. ${ }^{2}$ In contrast, in the second perspective, one would look much more carefully at the organization(s) that existed at time $(\mathrm{t}-1)$, at their connections between organization $\mathrm{x}$ and other institutions, and then try to tell an explicit historical account on how one got from the state at $(\mathrm{t}-1)$ to the state at $\mathrm{t}$. In this respect, the answer to "why something exists' relies a good deal on the account of how it came about in actual history, rather than in a stylized theoretical account.

We are not suggesting that the first account is institution-free and the second is agent-free. Consider, for example, Williamson (1995) (which certainly belongs to the 'rationalist' camp as defined here): he emphasizes that institutions can indeed

\footnotetext{
${ }^{2}$ For a useful discussion of this approach, see Granovetter (1995). As noted by Ogilvie (2007) in the strongest versions, the "efficient account" of institutions is completely oblivious of their potential role in the distribution of resources and power among social groups. Furthermore, the "efficiency account" tends to assume that one institution carries out only one specific "function".
} 
play a critical role in the setting of the parameters of the economic problem which has led to the emergence of a specific organization-in this case the optimization of transaction costs - and also exert a (weak) influence on the characteristics of the agents. Of course, institutions play a much more central role in the 'institutionalist' account by shaping and constraining the opportunities and motivations of the agents (Granovetter 1995). ${ }^{3}$ We would add that institutions also help shape the beliefs of the agents on what their interests are and about the instruments at their disposal to pursue them, in other words, their rationality.

The presumption in the strong versions of the 'rationalist tale' is that agents are endowed with cognitive abilities that are capable to provide a fairly accurate picture of the environment in which they are situated, allowing them to solve consistently the decision problems at hand. 'Boundedly rational' versions of this approach relax this assumption by allowing computational limitations, but still tend to define 'bounded' rationality as an imperfection and tend to focus the analysis on the difference between the optimal solution and the boundedly rational one.

At the opposite side of the camp, the 'institutionalist tale' has obviously major overlaps with all the approaches, such as cognitive psychology and sociology, which are rooted in the notion of pervasive "representation" and "competence" gaps (a) between what one sees and believes, and 'what is really out there'; and (b) between what one could notionally do, given the environmental constraints, and what one is actually capable of doing. As a result, in this view, the critical theoretical task is to investigate the nature and process of emergence and consolidation of particular cognitive frames, interpretative categories, patterns of behaviors and routines (to name just a few references within a large and heterogeneous literature, see Shafir and Tversky 1992, on reasoning and decision-making; Gigerenzer and Brighton 2009, on heuristics and problem-solving; Holland et al. 1986, and Lakoff 1987, on adaptive learning and category formation; and Nelson and Winter 1982; Cohen et al. 1996; Dosi and Egidi 1991; Becker 2005 on behavioral routines).

Similar considerations affect the distinction between the cognitive and motivational aspects of decision-making. Clearly, the 'rationalist tale' is based on the notion of a clear-cut disconnection between 'what one wants' and 'what one knows', and the agents is straightforwardly using what he knows, to get what he wants. Conversely, the 'institutionalist tale' is comfortable also with blurred border between these two dimensions of the decision making process, possibly resulting in endogenous changing preferences or coexisting contradictory models of cognition and action in the heads of the same individuals. ${ }^{4}$

\footnotetext{
${ }^{3}$ A version of the 'institutionalist perspective' attempting to comprise both the motivational drivers emphasized by the 'rationalists' (self-interested utility maximization), and other motivational factors (including moral and ethical ones), is the so-called 'socio-economic perspective' (Etzioni 1988). Incidentally, note that, as the latter approach shows, non-utilitarian motivations can be brought into the picture without giving up 'rational' (at least in the sense of purposeful and coherent) decision-making.

${ }^{4}$ Relevant discussions in these respects are Cohen et al. (1972), Earl (1983, 1992), Elster $(1979,1983)$. A thorough introduction is in March (1994). Clearly, the majority of economists tend to be more comfortable with the first tale and sociologists with the second. However, it is deeply misleading, in our view, to identify the dichotomy with disciplinary boundaries (a bit along the lines of Pareto, who equated economics and sociology with the study of 'rational' and 'irrational' behaviors respectively). In fact, we personally consider it good news that these diverse perspectives increasingly affect all social disciplines.
} 
Furthermore, the "rationalist tale" implies, as noted by McCloskey (1998), that economic self-interest must be the predominant motivational drive underlying all economic choices. In McCloskey 's view this assumption is at odds with Smith's (1759) view who developed a rich taxonomy of drivers of behaviors in which "utility" - roughly approximated by his notion of "prudence"-played a relatively minor part. Other relevant "pagan" and "Christian" behavioral drivers ranging from love to honor, from charitas to dignity played a major role in characterizing what human beings do even in the economic sphere (McCloskey 1998). The key issue is that given the interactions among motivational drives in the decision making process (and possibly even in the representation of the choice itself), approaches whose "primitives" assume exclusively economic self-interest as motivation can easily result in exceedingly reductionist interpretations of the dynamics of social change (McCloskey 1998, 2016). ${ }^{5}$

\section{Power, authority and hierarchies}

Alongside rationality, another related 'foundational' issue revolves around the nature of hierarchies, and the notion of power. Let us consider two simple ontological perspectives on the role hierarchies and power in social systems.

The first perspective suggests that (a) the notion of 'power' does not have any autonomous explicative power; (b) the fundamental unit of analysis is that of voluntary transactions among "free" agents; and (c) organizations are essentially governance structures. We shall label this approach the "exchange view" of organizations. The second perspective, which we shall call the "political view", holds, on the contrary, that (a) a salient, although not unique, feature of organizations is their hierarchical structure articulated in relations of authority; (b) authority/hierarchical relations cannot be reduced to exchange relations; (c) accordingly, power has an autonomous interpretative dimension, and cannot be interpreted in terms of a governance arrangements established as a result of voluntary exchanges. This second account encompasses a broad notion of power. First, power entails the ability of an agent (the "ruler", the authority) to define the set of actions available to the other agents (the "ruled"). Second, it involves the possibility of the authority to veto the decisions or intentions of the ruled ones. Third, power relates to the ability of the authority to influence or command the choice within the "allowed" choice set (i.e. the span of control of the "ruled"), according to the deliberations of the ruler himself (this definition echoes in some ways the analysis contained in Luhmann 1979).

\footnotetext{
5 An intriguing example of the interplay of motivational drivers affecting consumption choices is provided by the recent historical study of English consumers in the 1750-1821 period by Horrell et al. (2015). It is worth quoting their conclusions: "Our findings underline the importance of fashion and tastes, which exerted an independent influence on the ownership of all the items that we examined, but make space too for price and income effect. The relative magnitude of fashion, price and income varied according to the specific item considered, but none should be omitted in an account of the consumer revolution, which pour evidence suggests involved a complex interplay between desires and differentiation, and aspiration and affordability" (Horrel et al. 2015, p. 855).
} 
In this context, the units of analysis are the dimensionality and boundaries of the choice sets and the mechanisms by which authority is enforced. As Simon (1991, p. 31) puts it: "Authority in organizations is not used exclusively, or even mainly, to command specific actions. Most often, the command takes the form of a result to be produced ("repair this hinge"), or a principle to be applied ("all purchases must be made through the purchasing department") or goal constraints ("manufacture as cheaply as possible consistent with quality")". Fourth, the most subtle exercise of power concerns the influence of the authority upon the preferences of the ruled themselves, so that, in Weber's (1978, p. 946) words, the conduct of the ruled is such that it is "as if the rules had made the content of the command the maxim of their conduct for its own sake". That easily accounts for the fact that "organizations can be highly productive even though the relation between their goals and the material rewards received by employees, if it exists at all, is extremely indirect and tenuous" (Simon 1991, p. 38).

Obedience, docility, identification in social roles and in the organization are central elements of such processes of adaptive learning and coordination (classic discussion of these processes are in Milgram 1974; Simon 1976, 1981, 1993; Lindblom 1977; Lukes 2005; Moore 1958). Docility offers the inclination to "depend on suggestions, recommendation, persuasion and information obtained through social channels as a major basis for choice" (Simon 1993, p. 156). And, emphatically, such inputs are not inputs to any well-articulated decision process. In this view, both cognitive frames and preferences are endogenous to the very process of social adaptation and social learning. It is crucial to note that the social endogeneity of identity building is exactly the opposite to any type of decision-theoretic model: one learns socially not only what one can or cannot do, but, more fundamentally, what one wants, the very interpretation of the natural and social environment one lives in, and, ultimately, the self-perception and identity of the agents. Indeed, the conjecture we explore in Dosi and Marengo (2015) is that in many circumstances such processes of cognitive and behavioral adaptation yield also much more efficient and quicker coordination patterns, than those characterized by explicitly articulated form of decision processes.

The political view, of course, does not claim to be exhaustive: command and exchange relations coexist in different forms within and outside organizations. But it claims - at least as we interpret it - that looking only at exchange relations prevents a full understanding of what goes on within the 'organizational black box'. Indeed, exchange activities are not the prevailing forms of interactions in all domains of social life. Given these premises, it is very likely that an interpretation of organization only based on voluntary exchanges will miss essential features of the nature of organizations. Interestingly enough, this perspective on the role of power also links up with a significant Marxist literature. In a classic Marxist framework, the choiceset is essentially pre-determined by nature of relations of productions (Howard and King 1985). Interestingly enough, also subsequent contributions in Marxist sociology assessing the role of ideology and cultural hegemony in acting as "persuasion drivers" in favor of the ruling classes are in line with the perspectives just discussed that emphasize the role of power relations in shaping individual preferences (Hobsbawm 2012). 
Note also that the dichotomy between the exchange and political views overlaps, to a major degree, with the previous distinction between 'rationalist' and 'institutionalist' perspective on individual choices and behaviors. In fact, the political view calls for microfoundations featuring socially adaptive preferences and behavioral modes (such as 'obedience to authority ' or 'identification with social roles') ${ }^{6}$ quite at odds with the rationalist tale. On the other hand, any interpretation of organizations based on strong versions of the rationalist tale will result in the interpretation of almost any kind of authoritative interaction as governance relation which was generated by voluntary exchanges by free rational agents.

Ultimately, the rationalist tale-cum-exchange view entails a sort of unitary and invariant anthropology, based on well-formed, consistent interests as the basic motivational drives and criteria for action. At the other extreme, the institutionalist talecum-political view is naturally consistent with the idea of an irreducible multiplicity of motivational dimensions, and, possibly, with multiple 'identities' coexisting within the same agent. So, for example, the latter perspective builds upon broad historical generalizations such as Hirschman's (1977) account of the changing balance between 'passions' and 'interests' in modern Western culture or Sen's (1987) fascinating discussion of the (sometimes uneasy) coexistence between 'ethical' and 'economic' motives. The same phenomena would be interpreted in rationalist/exchange perspectives as varying restrictions on some sort of 'enlarged utility functions' or changing 'social technologies' for the governance of exchanges and production. ${ }^{7}$

Moreover, the 'institutionalist' perspective would consider exchanges themselves as embedded in particular institutions (e.g. 'the markets') whose origins and characteristics demand to be explained (on the notion of embeddedness, Granovetter 1985, 1995). Finally, note that the political view is quite in tune with the picture of business firms provided by most organizational theorists and business economists alike (Pfeffer 1981; Simon 1993).

\section{Weak and strong institutionalism}

From the "primitives" discussed in Sects. 2 and 3 stem major dichotomies on the very nature of hierarchies and power and of institutions more generally. We summarize them in Tables 1 and 2 .

Table 1 summarizes the two perspectives on power and hierarchies discussed in Sect. 3. In Table 2, we try to highlight the different approaches on institutions which can be articulated on the basis of the different basic assumptions concerning the functioning of social systems discussed so far. In our view, it is possible to introduce a distinction between a "weak" and a "strong" form of institutionalism, where

\footnotetext{
6 Classic discussions of these processes are in Milgram (1974), Simon (1976) and Lindblom (1977).

7 Of course, pushing the interpretation to the extreme, one reaches a Becker-type anthropology whereby, for example, the only remarkable difference between Adolf Hitler and Mother Theresa of Calcutta rests on diverse weights of the arguments of their (dimensionally identical) utility function and, analogously, the differences between Micronesian civilizations and New York yuppies can be reduced to differences in available social technologies.
} 
Table 1 Nature of hierarchies

\begin{tabular}{ll}
\hline "Exchange" view & "Political" view \\
\hline No analytical status to the notion of power & $\begin{array}{c}\text { Essential features of organizations are patterns of } \\
\text { power exercise and authority relations } \\
\text { Power/authority relations are essentially different } \\
\text { from exchange relations and therefore they have } \\
\text { apparent "power relations" can be explained by } \\
\text { asymmetric transactions }\end{array}$ \\
$\begin{array}{c}\text { Units of analysis include knowledge, organizational } \\
\text { forms, behavioral codes, routines, mental frames }\end{array}$ \\
$\begin{array}{c}\text { Organizations are "veils" covering sets of contracts } \\
\text { or bundles of incomplete contractual agreements }\end{array}$ & $\begin{array}{c}\text { Organizations are intrinsically different from } \\
\text { exchanges }\end{array}$ \\
\hline
\end{tabular}

the former has its roots in "exchange primitives" and includes the so-called neoinstitutionalism (prominently represented by North and Williamson), while the latter has its roots in political primitives, with such noble ancestors as Veblen and Polanyi.

And indeed the two archetypes differ also in terms of the relative role attributed to "choice" vs. "structure" in the determination of behaviors and in terms of the importance of history in the dynamics of institutions in general and formal organizations in particular. In particular, they differ in terms of:

- role attributed to individual rationality in the development of collective institutions,

- degree of path-dependency and inertia of institutions themselves,

- relative analytical importance of choice vs. constraints in individual and collective behaviors,

- the importance of history and institutions in shaping preferences and behaviors,

- the nature of hierarchies in the organizations in which agents operation.

Today, the neo-institutionalism paradigm (or weak institutionalism as it is labeled in this paper) is probably the predominant analytical outlook in economics. The success of the approach is possibly due by the adoption of a simple and straightforward representation of social institutions in terms of "rules of the game" (North 1991) combined with "rationalist tale" primitive. In this case, this amounts to standard economic assumptions concerning the rational behavior of individuals (allowing to describe individual decision-making using either parametric optimization algorithms or game theory, in cases, in contexts where strategic interaction assumers relevance). This set of standard assumptions can be used to formulate "theoretical tales" for the existence of a wide variety of institutional arrangements (Ogilvie 2007). ${ }^{8}$

Furthermore, it is worth noticing that, at least since the mid 1990s, the neo-institutionalist approach has been progressively refined in two main directions.

\footnotetext{
${ }^{8}$ For a very perceptive analysis of the connections between "neo-institutionalism" and neoclassical economics, see McCloskey (2016).
} 


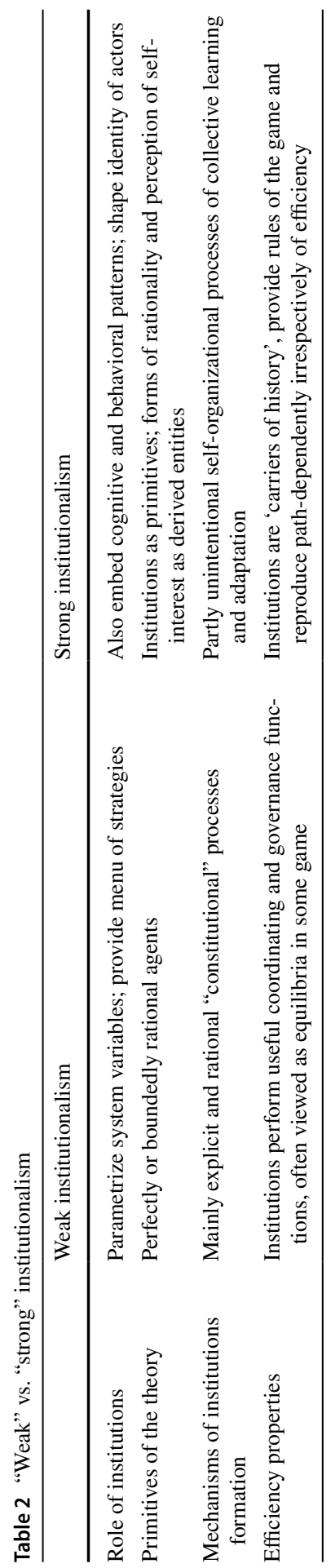


The first direction is the systematic application of the neo-institutionalist approach to historical cases of institutional change, with a particular view at examining the connection between institutional set-ups and economic performance. This stream of research is epitomized by the contributions of Acemoglu et al. (2005), Acemoglu and Robinson (2012). Interestingly enough, in order to work out a plausible connection between the stylized tale of institutions emerging from a "social contract" among free, self-interested and rational individuals with the actual historical record providing ample evidence of the emergence and persistence of institutional set-ups characterized by inequality and relationships of domination, Acemoglu, Johnson and Robinson are forced to introduce a distinction between political and economic institutions (Acemoglu et al. 2005). In this adapted framework, economic institutions are still essentially defined as the "rules of the game" in the economic sphere (e.g. property rights) endorsed by state in any given moment. Political institutions are, instead, the "rules of the game" governing the power of different social groups in shaping both economic and political "rules of the game" in any given moment. Changes in political institutions are essentially an outcome of the conflict among different social groups. Hence, whenever "narrow" elites have the power to dominate the political process, it is likely that the a country will be characterized by "extractive economic institutions" establishing relations of domination between different social groups and by sub-optimal economic performances. In this way, the neo-institutionalist research program moves away from the characterization of the processes of institutional change in terms of the negotiated "constitutional" agreements. Somewhat paradoxically, however, in most cases this results in nesting a very simplified "vulgar" Marxist view of political history into neoclassical microfoundations (Acemoglu and Robinson 2012). ${ }^{9}$

There is second major theme in the research program of Acemoglu and Robinson (2012) which is worth noticing: the study of the empirical connection between various types of institutions and economic performance. In most cases, this is carried out using synthetic and extremely crude indicators representing different institutional configurations (e.g., Polity IV type of data for representing political institutions).

In this perspective, most of the efforts have been devoted in the design of empirical frameworks which could ensure to tackle effectively the issue of the potential endogeneity of the institutional variable with respect to economic performance. In general, the key finding of Acemoglu et al. 2005 and their associates is that economic institutions establishing secure and clearly defined property rights and a smooth functioning of markets are to be regarded as the major source of long-run economic growth. This, of course, is a predicament that most neoclassical economists have put forward for long time. The success enjoyed by Acemoglu and Robinson (2012) arises from the widespread impression that their research has finally provided a rigorous analytical and empirical background for this notion. In fact, at closer inspection, the approach of Acemoglu and Robinson (2012), despite its sophistication, seems not able to provide major insights both on the processes of institutional change and on the connection between institutions and economic

\footnotetext{
${ }^{9}$ For a devastating review of Acemoglu and Robinson (2012), see Vries (2012).
} 
performance. The major limit is that the approach provides a characterization of institutional set-ups that is extremely crude, despite its apparent clarity. Acemoglu and Robinson (2012) do not take into account the complex relationship between institutional set-ups and their outcomes both in terms of economic performance and inequality. For example, let us consider an institution such as medieval guilds. It turns out that, the economic interpretation is far from obvious. On the one hand, the institution can be seen simply as barrier to entry in production protecting the rents of incumbents. On the other hand, in the medieval economy, guilds were performing a number of other functions such as enhancing the transmission of skills or mitigating credit market imperfections (Ogilvie 2007). As a result, it becomes difficult to ascribe to any institutions a specific "function" within the economic and social system and, relatedly, to provide a comprehensive assessment of its political and economic effects, without taking the wider context in which the institution was operating (Ogilvie and Carus 2014). Furthermore, each institution is likely to interact in complex ways with other institutions. All this suggests that providing characterizations of institutional set-ups using generic terms such as "secure property rights", "state capacity", etc. run the risk of conflating under the same heading highly heterogeneous phenomena. This shortcoming clearly also affects the construction of synthetic quantitative indicators of institutional set-ups. Finally, one can also notice that the Acemoglu-Robinson historical meta-narrative is also rather cavalier with respect to the historical record which registers prominent examples of countries such as Soviet Russia, or more recently China, that were able to launch large scale industrialization processes adopting institutional frameworks that were a far-cry from the "inclusive institutions" outlined by Acemoglu and Robinson (2012) (for a useful analysis of the Russian experience of industrialization, see Allen 2009, and for a general reassessment of industrialization emphasizing the role of state capacity rather than inclusive institutions, see Allen 2011).

The second direction of development of "weak institutionalism" is the attempt of including a cultural dimension in the process of institutional formation. The main approach in this vein is Greif (2007). Again, prima facie, given our discussion in the previous section, this seems to be a promising development. However, it should be noted that the cultural dimension is essentially introduced in terms of "parametric" restrictions in the game theoretic framework, that is, the matrix of economic payoffs becomes conditioned by a number of "exogenously" given cultural traits (for example, the existence of "collectivist" or "individualistic" attitudes). The behavioral of individuals is still described in terms of straightforward economic maximization. Again, this is a far-cry from the complex approach to decision making of the "institutionalist tale" that we have discussed in the first sections. Furthermore, the empirical operationalization of the approach is doubtful. In most cases, the parameters of the game do not lend themselves to a straightforward empirical characterization (Clark 2007). Hence, again the approach is dangerously on the border of the "functionalist fallacy" of attributing to institutional set-ups specific functions, on the 
grounds of the existence of some abstract game-theoretic equilibrium. ${ }^{10}$ On the other hand, it is interesting to note that the "strong institutionalist" perspective outlined here rejects the notion that culture and institutions may be independent determinants of economic performance (Acemoglu et al. 2005). In fact, in this perspective the very functioning of institutions cannot be disentangled by cultural norms, values, beliefs and cognitive frames. Of course, this amounts to a much more complex perspective which possibly implies that synthetic quantitative measurements of institutions or of cultural traits (e.g., social capital) ought to be handled with extreme care. $^{11}$

\section{Origins, dynamics and efficiency properties of organizations}

The multidimensional nature of institutional arrangements has far-reaching implications for the study of the efficiency properties of organizations. Let us focus on the question of 'why organization x exists'. As already mentioned, there are two possible answers. The first one is based on an explicit account of its historical origins (i.e. how the organization became what it is today). This, of course, is the approach adopted by business historians to interpret the evolution of organizations. The second possible answer is a functionalist explanation. It formulates necessary and sufficient reasons for the existence of the organization in question from the task it performs today and its efficiency properties. Admittedly, using the first historical approach, it might be quite difficult to formulate general interpretations, since this would involve the identification of classes of processes and sets of initial conditions yielding as outcomes the formation of similar forms of institutional arrangements. But, with the second interpretation, it is far too easy to succumb to functionalist or theological fallacies, as forcefully argued by Granovetter (1995). In this respect, the challenge would be to demonstrate that functional efficiency is a robust outcome of either intentional constructive processes or collective, unintentional mechanisms of selection among a variety of alternative organizational solutions.

It is fair to say that, so far, it has been very difficult to assemble compelling empirical evidence for this interpretation when dealing with actual historical instances of specific institutional arrangements. On the constructive, intentional side, the gametheoretic approach does not seem able to deliver the goods (Ogilvie 2007). Without entering into any detailed discussion of the state of the art, one should just recall the hurdles facing selection among multiple equilibria or the implications of the Folk theorem in repeated games (which basically says that any behavioral sequence that one observes can be interpreted as an equilibrium strategy).

An alternative explanation, adumbrated above, is to rely on a rudimentary evolutionary argument, by assuming that the organizations we see today are the outcome

\footnotetext{
${ }^{10}$ For a criticism of Greif's interpretation of the coalition of the Maghrebi traders, see Ogilvie and Carus (2014, pp. 411-416).

11 This perspective is actual close to the original contribution of Putnam et al. (1996) where institutions are generally seen as embedded in cultural attitudes.
} 
of an unspecified selection process. This argument is, of course, reminiscent of Milton Friedman (1953) as-if example of the pool player. However, apart from a lot of hand waving, the analytical results are mainly negative: only under quite restrictive conditions on the selection space, selection mechanisms and initial conditions does such an outcome obtain (Winter 1975, and the critical surveys in Silverberg 1988; Hodgson 1993). ${ }^{12}$

To sum up, it seems to us that no matter what kind of explanation one offers as to why particular organizations exist, an answer to the 'how' question is unavoidable. This, in turn, implies some historical reconstruction of how formal organizations - and, more generally, institutional arrangements - have emerged and changed over time. To develop, again, our argument in terms of dichotomic meta-narratives, one can find in the literature two main approaches accounting for the emergence of organizations. The first meta-tale-which we can label the constitutional model-is based on the idea of an intentional original agreement among self-interested, forward-looking agents who try to establish an effective governance structure and a corresponding set of formal and informal rules which would permit them to carry out cooperatively a well-defined set of tasks. In contrast, one may conceive the origin and evolution of organizations primarily in terms of largely unintentional outcomes of interactions in which governance structures and rules are "experimentally" adapted in order to ensure a more effective accomplishment of the tasks at hand. This latter perspective can be labeled as the "self-organization" model (Warglien 1995). Needless to say, the actual empirical processes of organizational formation are likely to involve different mixtures between the "constitutional" and "self-organization" perspectives, but the careful study of the application of each approach in specific cases can enhance our understanding of which kinds of interaction mechanism can result in certain type of organizational structures. Ostrom and Crawford (1995) is one fruitful example of the intertwining of both processes.

Whatever dynamic story one tells, it naturally involves the question of where the dynamics is leading to (which economists, perhaps too easily, confine to the nature of asymptotic properties of the process). And, symmetrically, one may ask the question of whether one would have got to a certain observed state, say, a certain organizational setup at time t, irrespectively of any initial conditions, further back in time. When initial conditions matter and their effect is not vanishing but possibly selfreinforcing over time, one says that the process is path-dependent. Hence, simplifying to the extreme, an integral part of the explanation of 'where one is going' or 'why we are here' is the account of 'where we come from'. Conversely, note that a necessary (although not sufficient) condition for a 'teleological' interpretation of an observed organizational phenomenon is the lack of path-dependency. As David (1992, p. 3) puts it,

whether the focus falls upon the supposed evolutionary tendency toward efficiency in the development of property rights and other macro-institutional

\footnotetext{
${ }^{12}$ For a perceptive discussion functionalist fallacies in evolutionary settings, see Gould and Lewontin (1979).
} 
arrangements, or upon the conceptualization of a firm's internal organization and mode of doing business as the consequence of rational, optimizing decisions, the implicit presumption [is] that institutional arrangements are perfectly malleable ...

David (1992) suggests at least four reasons why one should expect path-dependency in organizations and institutions. First, they incorporate shared conventions and mutually consistent expectations grounded in 'shared historical experiences and conscious perceptions of the shared past' (David 1992, p. 9). Second, they provide 'role-typing' and acculturation mechanisms which is a sort of 'sunk capital' of organizations (on this point, see also Douglas 1986). Third, they embody 'codes' for communication and information processing. Fourth, the interrelatedness of different organizational functions reinforces the resilience of specific organizational structures, possibly well beyond the time of their purported usefulness. ${ }^{13}$

\section{Incentives vs. authority vs. capabilities as determinants of organizational behaviors and performances}

The foregoing ontological divides yield also different answers to basic questions such as why economic institutions (and more specifically, formal organizations) other than markets exists, and what they do. As extensively discussed above, a good deal of contemporary theory starts the interpretation of the nature of organizations, including economic organizations basing it on sophisticated, self-interested agents. Together, the behaviors of these self-interested actors are viewed as typically directed by market forces. Only in those settings in which, due to failures of information and contract incompleteness, markets are less effective in this task, are organizations called for to surrogate such imperfections. It is a story too familiar to be repeated here.

Conversely, a small—but not negligible and growing - minority of the economic profession has identified the (first approximation) 'primitives' of the analysis in the problem-solving features of economic organizations, in turn nested in ubiquitous forms of human 'bounded rationality', grossly imperfect processes of learning and diverse mechanisms of the social distribution of 'cognitive labor'. Needless to say, it is a perspective that finds seminal roots in the works of Herbert Simon, James March and indeed Richard Nelson and Sidney Winter.

Let us offer the following thought-experiment to illustrate the differences between the two interpretative philosophies. Suppose that two delegations of intelligent but totally uninformed beings from Mars are sent to Earth with the mandate of reporting 'what business firms are'. The delegations are not allowed to visit the firms themselves. Rather, the first one is given to read, out of an enormous literature, say,

\footnotetext{
13 David (1992) uses, appropriately, the analogy with technological relatedness, whereby technical interdependence within complex systems makes it hard to change any one component without affecting the whole structure.
} 
Holmstrom and Tirole (1989) and Grossman and Hart (1986), while the second is given March and Simon (1958), Cyert and March (1992), Nelson and Winter (1982), and Marengo et al. (2000).

What would they report back to Mars? (We reasonably assume that these entities, given their empirical naïveté, are unable to catch all the caveats from footnotes, side remarks, etc.). Well, the first delegation would probably convey the idea that earthly firms are places where one confines vicious and cunning people who are made to play extremely sophisticated games according to rules designed in order to prevent them from doing much harm to themselves and to others. Only casual mention would be made - if at all - to conventional labels by which the outcomes are denominated ('steel', 'shoes', 'computers', and so on), while lengthy accounts would be devoted to the details of the admissible rules and the mathematical equipment humans utilize in order to figure out how to behave.

The second delegation is likely to return with a strikingly different story. It would probably begin with a rather long description of the impressive variety of 'things' that each day come out of earthly firms-i.e. precisely, steel, computers, polypropylene, etc. - and the equally impressive diversity in the processes leading to them. Moreover, these Martians would almost certainly remark that no one has the entire plan of what to do in their heads. Most of the members of each organization repeatedly undertake recognizably few operations, yet nevertheless organizations coordinate their tasks in ways generally yielding coherent artefacts at the end of the day. Indeed, this second delegation is likely to suggest the analogy of a 'firm' with a messy but most often reliable computer program, with little mention of possible conflict of interests among the individual carriers of various 'subroutines.'

Notwithstanding its being a caricature, the foregoing story does convey the spirit of an actual major divide cutting across current theorizing about organizations, having at the two extremes a pure incentive-governance view versus a pure problemsolving view.

Clearly, there are elements of truth in both perspectives (Coriat and Dosi 1998). An ambitious research program ahead entails indeed connecting the two. The starting point for such a bridge building has important consequences for the sort of bridge that one creates. The starting point embodies a commitment to some assumptions on first-order versus second-order effects. Forced to such a choice, we certainly pick the second perspective as a provisional point of departure (which also happens to be the least explored one). We do need to assume a weak incentive compatibility to begin with (Dosi and Marengo 1995) in the loosest sense that there exists some pressure (economic or not) generating some connection between performance and rewards. However, having that, one precisely focuses (as a first theoretical approximation) on the diverse problem-solving characteristics of different organizations, and only in the second instance one tackles the ways in which incentive structures interact with problem-solving knowledge.

Putting it in another way, the archetype 'incentive view' fully censors any competence issue associated with what organizations do and how well they do it-except for issues of misrepresentations of 'intrinsic' individual abilities and adverse selection, or incentive misalignment in effort elicitation. As an extreme characterization, 
given the 'right' incentives, any firm can make microprocessors as well as Intel, or bioengineering as well as Genetech.

The second, 'problem-solving', archetype, on the contrary, censors precisely the incentive-alignment issue. In a sense, all agents are 'angels' as their motives are concerned. Conversely, it focuses on the problem-solving efficacy of what they do, especially in so far as what they do does not stem from any differential 'ontological' ability but rather from the social division of tasks and their combinatorics. So, in the first approximation of this latter view, the basic units of analysis are elementary physical acts, such as moving a piece of iron from one place to another, and straightforwardly understood as combinations of elementary acts, within a procedure, leading to a feasible outcome (an engine, a chemical compound, etc.). ${ }^{14}$

One can also describe it the other way round. Given all the problem-solving procedures leading to a given 'outcome' (e.g. an engine, etc., and, for that matter, a theorem, a statement about the purported structure of the observed world) — which might well be an infinite set-one may decompose them in subsequences of elementary acts of varying length that may be eventually performed according to various execution architectures (sequential, parallel, hierarchical, etc.).

At this level of analysis, an organization embodies problem solving in at least three senses. First, it displays the operational competencies associated with its actual problem-solving procedures [much in accordance with the routines discussed in Nelson and Winter (1982); see also Cohen et al. (1996)]. Secondly, the organizational structure-both the formal and informal ones-determines the distribution of informational inputs of the processing tasks and of the 'allowable acts' (i.e. 'who can do what to whom') and, as such, it determines all the decompositions of problem-solving procedures that are, so to speak, 'legal'. Thirdly, it shapes the search heuristics for yet-unsolved problems-e.g. a new engine, a new chemical compound.

\section{Some conclusions as an invitation to join a largely unexplored research program}

Where this leads us? In our view, it is time we went back to and tried to rigorously operationalize the intuitions of such founding fathers as Smith, Marx, Dewey, Weber, Veblen, Commons, all the way to Hirschman, Simon, and a few others.

The vast majority of economists have taken a short-cut which interprets institutions using an efficiency criterion, founded on the principles of preference-based individual rationality (possibly suffering limitations that require second best institutions) and on equilibrium interactions. Also evolutionary game-theoretic accounts of the emergence of institutions just relax the rationality hypothesis, but supplement it with an "as-if" account of collective rationality emerging out of the selection process. This resulted in a Panglossian approach which assumes that what exists must be efficient at least in the long term, even if it has always failed to prove that efficiency will indeed be the outcome of some reasonable evolutionary dynamics (as

${ }^{14}$ See Marengo et al. (2000) for further discussion of this point. 
decisively shown by Winter 1975). Indeed, the New Institutional Economics and Williamson's (1981) Transaction Costs theory are not immune from such "Panglossianism" (as remarked by Granovetter 1985; Hodgson 1991).

In such a perspective the market is the only fully efficient first-best institution. Actually, the market precedes all other institutions as a sort of state of nature. ${ }^{15}$ Paradoxically, this assumption has induced economists, including those embracing the New Institutional Economics perspective, to focus mainly on the problem of the "nature of the firm"- puzzled by its very existence!- , and, with much less emphasis, on the "nature of the other non-market institutions", while entirely neglecting the problem of the "nature of market" (Hodgson 1988). If neoclassical economic theory has long suffered from a striking neglect of the institutional nature of firms, still today is mostly suffering from a perhaps even more astonishing neglect of the institutional nature of the market. Even Douglass North (1981, p. 41) points out this paradoxical state of affairs: "All the modern neoclassical literature discusses the firm as a substitute for the market [and] ignores a crucial fact of history: hierarchical organization forms and contractual arrangements in exchange pre-date the price making market'.

In our view, the major challenge ahead is to develop and operationalize a rigorous theory of the nature and dynamics of institutions which departs from any (undemonstrated) postulate of efficiency and market centrality and addresses the coevolution of organizations, "forms of rationality", preferences and technologies, i.e. precisely those elements that the neoclassical theory, but also a large part of the New Institutional Economics, consider as exogenously given "primitives". An important corollary is the institutional embeddedness of techno-economic change. The standard view is that technology is exogenously determined and sets the constraints which organizations optimally adapt to (and even attempts to make it "endogenous", rationalize it as the outcome of an optimal forward looking allocation of resources). Contrast this view with the alternative one, supported by vast empirical evidence, that these techno-economic changes are largely influenced by the institutional arrangements at all levels: national and international institutions, scientific and technological communities, organizational forms, work relations, etc. The cumulative and path-dependent pattern of change shapes the set of possible trajectories, while the ubiquitous complementarities among institutions, technologies, values, norms determine a multiplicity of evolutionary paths. Institutions are "the carriers of history" (David 1994), which well survive beyond any original "efficiency", if they ever had one.

Last but not least, institutions shape and constrain the processes of self-organized coordination which socio-economic dynamics typically display. We have been beating enough the purported dead horses of decision-theoretic and game-theoretic interpretations. Rather, in multi-agents set-ups, coordination is typically the outcome of self-organizing processes stemming from the local interactions among agents. Kirman (2011) makes a general, very convincing, case to the point-from bees and ants all the way to markets in general and financial markets in particular-.

15 "In the beginning, there were the markets" (Williamson 1975, p. 20). 
The focus, in this perspective, and rightly so, is on the aggregate orderly properties of local interactions, with not too much attention on the background constraints. So, of course, it would be meaningless to start describing the fascinating self-organizing order in the flights of flocks of birds by their constraints. By the same token, however, at the opposite extreme it would be equally foolish to start the description of a camp of war prisoners or Sing Sing inmates focusing on their self-organizing patterns, even if there often are indeed also under the most constraining institutional structures (Recall the tragic account of a nazi lager by Levi 1959).

Most human institutions are placed in between the two foregoing extremes: the interpretative challenge is indeed to understand the varying balances between distributed agency, if any, on the one hand; hard institutional, typically hierarchical, constraining institutions, on the other (indeed major anthropological studies such as Malinowski 1922; Levi Strauss 1973, seems to suggest not much room for individual agencies) and possibly their coupled dynamics, again when there is any.

We do believe that research in these directions would draw social sciences back to the "Enlightened" Founding Fathers of the social sciences paradigm, and away from the dogmatic stalemate in which today they are largely confined.

Acknowledgements This work is significantly based upon Dosi (1995), Dosi et al. (2005), and Dosi and Marengo (2015), Dosi and Roventini (2016), but builds upon a larger and expanding community of scholars painstakingly trying to depart from the prevailing Ptolemaic paradigm of economic theory founded on the primitives of utility maximization and equilibrium. We gratefully acknowledge the support by the European Union's Horizon 2020 Research and Innovation program under Grant Agreement No. 649186-ISIGrowth.

\section{References}

Acemoglu, D., Johnson, S., \& Robinson, J. (2005). Institutions as a fundamental cause of long run economic growth. In P. Aghion \& S. Durlauf (Eds.), Handbook of economic growth. Dordrecht: Elsevier.

Acemoglu, D., \& Robinson, J. (2012). Why nations fail. London: Profile Books.

Allen, R. C. (2009). Farm to factory. A reinterpretation of the Soviet industrial revolution. Princeton: Princeton University Press.

Allen, R. C. (2011). Global economic history. A very short introduction. Oxford: Oxford University Press.

Becker, G. (1976). The economic approach to human behaviour. Chicago: Chicago University Press.

Becker, M. (2005). A framework for applying organizational routines in empirical research: Linking antecedents, characteristics and performance outcomes of recurrent interaction patterns. Industrial and Corporate Change, 14, 817-846.

Clark, G. (2007). A review of Avner Greif's institutions and the path to the modern economy. Journal of Economic Literature, 45, 727-743.

Cohen, M. D., Burkhart, R., Dosi, G., Egidi, M., Marengo, L., Warglien, M., et al. (1996). Routines and other recurring action patterns of organizations: Contemporary research issues. Industrial and Corporate Change, 5, 653-698.

Cohen, M. D., March, J. G., \& Olsen, J. P. (1972). A garbage can model of organizational choice. Administrative Sciences Quarterly, 17, 1-25.

Coriat, B., \& Dosi, G. (1998). Learning how to govern and learning how to solve problems: on the coevolution of competences, conflicts and organizational routines. In A. Chandler, P. Hagström, \& Ö. Sölvell (Eds.), The Dynamic Firm. Oxford: Oxford University Press. 
Cyert, R. M., \& March, J. G. (1992). A behavioral theory of the firm (2nd ed.). Cambridge: Basil Blackwell.

David, P. (1992). Path dependence and predictability in dynamic systems with local externalities: a paradigm for historical economics. In D. Foray \& C. Freeman (Eds.), Technology and the wealth of nations (pp. 208-231). London: Pinter.

David, P. (1994). Why are institutions the 'carriers of history'?: Path dependence and the evolution of conventions, organizations and institutions. Structural Change and Economics Dynamics, 5(2), 205-220.

Dosi, G. (1995). Hierarchies, markets and power: Some foundational issues on the nature of contemporary economic organizations. Industrial and Corporate Changevol., 4, 1-19.

Dosi, G., \& Egidi, M. (1991). Substantive and procedural uncertainty. An exploration of economic behavior in changing environments. Journal of Evolutionary Economics, 1, 145-168.

Dosi, G., \& Marengo, L. (1995). Toward a theory of organizational competencies. In R. W. England (Ed.), Evolutionary concepts in contemporary economics. East Lansing: Michigan University Press.

Dosi, G., \& Marengo, L. (2015). The dynamics of organizational structures and performances under diverging distributions of knowledge and different power structures. Journal of Institutional Economics, 11, 535-559.

Dosi, G., Marengo, L., \& Fagiolo, G. (2005). Learning in evolutionary environments. In K. Dopfer (Ed.), The evolutionary foundations of economics (pp. 255-328). Cambridge: Cambridge University Press.

Dosi, G., \& Roventini, A. (2016). The irresistible fetish of utility theory: From "pleasure and pain" to the rationalization of torture. Intereconomics, 51, 286-287.

Douglas, M. (1986). How institutions think. Syracuse: Syracuse University Press.

Earl, P. E. (1983). The economic imagination. Brighton: Wheatsheaf.

Earl, P. E. (1992). On the complementarity of economic applications of cognitive dissonance and personal construct psychology. In S. E. G. Lea, P. Webley, \& B. Young (Eds.), New directions in economic psychology. Aldershot: Edward Elgar.

Elster, J. (1979). Ulysses and the Sirens. Cambridge: Cambridge University Press.

Elster, J. (1983). Explaining technical change: A case study in the philosophy of science. Cambridge: Cambridge University Press.

Etzioni, A. (1988). The moral dimension, toward a new economics. New York: The Free Press-.

Friedman, M. (1953). Essays in positive economics. Chicago: University of Chicago Press.

Gigerenzer, G., \& Brighton, H. (2009). Homo heuristicus: Why biased minds make better inferences. Topics in Cognitive Science, 1, 107-143.

Gould, S., \& Lewontin, R. (1979). The spandrels of San Marco and the Panglossian paradigm: a critique of the adaptationist programme. Proceedings of the Royal Society, 205, 581-598.

Granovetter, M. (1985). Economic action and social structure: The problem of embeddedness. American Journal of Sociology, 91, 481-510.

Granovetter, M. (1995). Coase revisited: Business groups in the modern economy. Industrial and Corporate Change, 4(1), 93-130.

Greif, A. (2007). Institutions and the path to the modern economy. Cambridge: Cambridge University Press.

Grossman, S. J., \& Hart, O. D. (1986). The costs and benefits of ownership. Journal of Political Economy, 94, 691-719.

Hirschman, A. (1977). The passions and the interests: Political arguments for capitalism before its triumph. Princeton: Princeton University Press.

Hobsbawm, E. (2012). How to change the world. Reflections on Marx and Marxism. Yale: Yale University Press.

Hodgson, G. (1993). Economics and evolution: Bringing life back into economics. Cambridge: Polity Press.

Hodgson, G. M. (1988). Economics and institutions. Cambridge: Polity Press.

Hodgson, G. M. (1991). Economic evolution, intervention contra Pangloss. Journal of Economic Issues, 25 , 519-533.

Holland, J. H., Holyoak, K. J., Nisbett, R. E., \& Thagard, P. R. (Eds.). (1986). Induction: Processes of inference, learning and discovery. Cambridge, MA: MIT Press.

Holmstrom, B., \& Tirole, J. (1989). The theory of the firm. In R. Schmalensee \& R. Willig (Eds.), Handbook of industrial economics. Amsterdam: Elsevier Publishing.

Horrell, S., Humphries, J., \& Sneath, K. (2015). Consumption conundrums unravelled. Economic History Review, 68, 830-857.

Howard, M., \& King, J. (1985). The political economy of Marx. New York: New York University Press.

Kirman, A. (2011). Complex economics. Abingdon: Routledge.

Laing, R. D., \& Esterson, A. (1970). Sanity, madness and the family. Oxford: Pelican Family. 
Lakoff, G. (1987). Women, fire and dangerous things: What categories reveal about the mind. Chicago: University of Chicago Press.

Levi, P. (1959). If this is a man. New York: The Orion Press.

Levi Strauss, C. (1973). Tristes tropiques. New York: Atheneum.

Lindblom, C. (1977). Politics and markets. New York: Basic Books.

Luhmann, N. (1979). Trust and power. Chichester: Wiley.

Lukes, S. (2005). Power: A radical view. London: Palgrave MacMillan.

Malinowski, B. (1922). Argonauts of the Western Pacific. London: Routledge.

March, J. G. (1994). A primer on decision making: How decisions happen. New York: Free Press.

March, J. G., \& Simon, H. A. (1958). Organizations. New York: Basil Blackwell.

Marengo, L., Dosi, G., Legrenzi, P., \& Pasquali, C. (2000). The structure of problem-solving knowledge and the structure of organizations. Industrial and Corporate Change, 9, 757-788.

McCloskey, D. N. (1998). Bourgeois virtues and the dynamics of P and S. Journal of Economic History, 58, 297-317.

McCloskey, D. N. (2016). Max U versus humanomics: A critique of neo-institutionalism. Journal of Institutional Economics, 12, 1-27.

Milgram, S. (1974). Obedience to authority; An experimental view. London: Tavistock Institute.

Moore, B. (1958). Political power and social theory: Six studies. Cambridge, MA: Harvard University Press.

Nelson, R. R., \& Winter, S. G. (1982). An evolutionary theory of economic change. Cambridge, MA: Harvard University Press.

North, D. (1981). Structure and change in economic history. New York: Norton.

North, D. (1991). Institutions. Journal of Economic Perspectives, 5, 97-112.

North, D. (2005). Understanding the process of economic change. Princeton: Princeton University Press.

North, D., \& Thomas, R. P. (1973). The rise of the western world: A new economic history. Cambridge: Cambridge University Press.

Nuvolari, A. (2016). Douglass C. North, 1920-2015. History of Economic Ideas, 24, 9-13.

Ogilvie, S. (2007). Whatever is, is right? Economic institutions in preindustrial Europe. Economic History Review, 60, 649-684.

Ogilvie, S., \& Carus, A. W. (2014). Institutions and economic growth in historical perspective. In P. Aghion \& S. Durlauf (Eds.), Handbook of economic growth. Dordrecht: Elsevier.

Ostrom, E., \& Crawford, S. E. (1995). A grammar of institutions. American Political Science Review, 89, 582-600.

Pfeffer, J. (1981). Power in organizations. Marshfield, MA: Pitman.

Putnam, R. D., Leonardi, R., \& Nanetti, R. Y. (1996). Making democracy work: Civic traditions in modern Italy. Princeton: Princeton University Press.

Sen, A. (1987). The standard of living. Cambridge: Cambridge University Press.

Shafir, E. B., \& Tversky, A. (1992). Thinking through uncertainty: inconsequential reasoning and choice. Cognitive Psychology, 24, 449-474.

Silverberg, G. (1988). Modelling economic dynamics and technical change: mathematical approaches to self-organisation and evolution. In G. Dosi, C. Freeman, R. Nelson, G. Silverberg, \& L. Soete (Eds.), Technical change and economic theory. London: Pinter.

Simon, H. (1976). Admistrative behavior: A study of decision-making processes in administrative organizations (3rd ed.). New York: The Free Press.

Simon, H. (1981). The sciences of the artificial (2nd ed.). Cambridge, MA: MIT Press.

Simon, H. (1991). Organizations and markets. Journal of Economic Perspectives, 5, 25-44.

Simon, H. (1993). Altruism and economics. American Economic Review, 83, 156-161.

Smith, A. (1759). Theory of moral sentiments. Lexington: Economic Classics (EMP).

Vries, P. (2012). Does wealth entirely depend on inclusive institutions and pluralist politics? Tidjschrift voor Sociale und Economische Geschiedenis, 9, 74-92.

Warglien, M. (1995). Hierarchical selection and organizational adaptation. Industrial and Corporate Change, 1, 161-186.

Weber, M. (1978). Economy and society. An outline of interpretive sociology. Oakland: University of California Press.

Williamson, O. E. (1975). Markets and hierarchies: Analysis and antitrust implications. New York: Free Press.

Williamson, O. E. (1981). The economics of organization: The transaction cost approach. American Journal of Sociology, 87(3), 548-577. 
Williamson, O. (1995). Hierarchies, markets and power in the economy: An economic perspective. Industrial and Corporate Change, 4, 21-49.

Winter, S. G. (1975). Optimization and evolution in the theory of the firm. In R. H. Day \& T. Groves (Eds.), Adaptive economic models (pp. 73-118). New York: Academic.

Publisher's Note Springer Nature remains neutral with regard to jurisdictional claims in published maps and institutional affiliations.

\section{Affiliations}

\section{Giovanni Dosi $^{1} \cdot$ Luigi Marengo $^{2} \cdot$ Alessandro Nuvolari $^{1}$}

Giovanni Dosi

g.dosi@sssup.it

Luigi Marengo

lmarengo@luiss.it

1 Institute of Economics, Scuola Superiore Sant'Anna, Pisa, Italy

2 Department of Business and Management, LUISS, Rome, Italy 